\title{
Predictive values of upper gastrointestinal cancer alarm symptoms in the general population: a nationwide cohort study
}

Sanne Rasmussen, Peter Fentz Haastrup * (D), Kirubakaran Balasubramaniam, René DePont Christensen, Jens Søndergaard and Dorte Ejg Jarbøl

\begin{abstract}
Background: Survival rates for upper gastrointestinal (Gl) cancer are poor since many are diagnosed at advanced stages. Fast track endoscopy has been introduced to prompt diagnosis for patients with alarm symptoms that could be indicative of upper Gl cancer. However, these symptoms may represent benign conditions and little is known about the predictive values of alarm symptoms of upper Gl cancer in the general population.

Methods: The study is a nationwide cohort study of 60,562 individuals aged 45 years or above randomly selected from the Danish general population. Participants were invited to complete a survey comprising of questions on several symptom experiences, including alarm symptoms for upper Gl cancer within the past four weeks. The participants were asked about specific symptoms (repeated vomiting, difficulty swallowing, signs of upper Gl bleeding or persistent and recent-onset abdominal pain) and non-specific symptoms (nausea, weight loss, loss of appetite, feeling unwell and tiredness).

We obtained information on upper Gl cancer diagnosed in a 12-month period after completing the questionnaire from the Danish Cancer Registry. We calculated positive predictive values and positive likelihood ratios for the association between alarm symptom and subsequent upper $\mathrm{Gl}$ cancer.

Results: A total of 33,040 individuals above 45 years completed the questionnaire, yielding a response rate of 54.6\%. Respondents were fairly respresentative of the study sample. During the follow-up period, 18 people were diagnosed with upper $\mathrm{Gl}$ cancer. The number of incident cancers was similar among eligible non-respondents. Two thirds of the respondents with an upper GI malignancy had experienced one or more alarm symptoms.

The positive predictive value for being diagnosed with upper $\mathrm{Gl}$ cancer after reporting a least one alarm symptom was 0.1\% (95\% Cl:0.0-0.1\%). The positive likelihood ratio was 4.4 for specific alarm symptoms and 1.1 for non-specific alarm symptoms.

Conclusions: We found that positive predictive values of alarm symptoms of upper $\mathrm{Gl}$ cancer experienced in the general population are low. It is important knowledge that despite denoted alarm symptoms even patients with specific alarm symptoms of upper Gl cancer have a low risk of being diagnosed with upper Gl cancer.
\end{abstract}

Keywords: Oesophagogastric cancer, Symptom, Diagnosis, Primary health care, Survey

\footnotetext{
* Correspondence: phaastrup@health.sdu.dk

Research Unit of General Practice, Department of Public Health, University of

Southern Denmark, J. B. Winsløws Vej 9A, 5000 Odense C, Denmark
}

(c) The Author(s). 2018 Open Access This article is distributed under the terms of the Creative Commons Attribution 4.0 International License (http://creativecommons.org/licenses/by/4.0/), which permits unrestricted use, distribution, and reproduction in any medium, provided you give appropriate credit to the original author(s) and the source, provide a link to the Creative Commons license, and indicate if changes were made. The Creative Commons Public Domain Dedication waiver (http://creativecommons.org/publicdomain/zero/1.0/) applies to the data made available in this article, unless otherwise stated. 


\section{Background}

The incidence of upper gastrointestinal (GI) cancer comprising oesophageal and gastric carcinomas is modest in the Western world. However, upper GI cancers are serious diseases with substantial morbidity and mortality. The prognosis depends on the stage of disease at diagnosis and since many are diagnosed at advanced stages, the five-year survival rates are poor [1]. Approximately one third of the patients with upper GI cancer are diagnosed following emergency presentation [2], which is associated with poorer outcomes [3]. Referral guidelines for fast track endoscopy have been implemented to expedite diagnosis in order to avoid emergency presentation and to diagnose these cancers at less advanced stages [4, 5]. The guidelines give access to fact track endoscopy for patients presenting specific alarm symptoms indicative of upper GI cancer such as blood in vomit and new onset dyspepsia in individuals over 45 years. We have previously reported that specific alarm symptoms of upper GI cancer are not very prevalent in the general population [6]. Much of the evidence supporting referral guidelines derive from secondary care settings and patients already diagnosed with upper GI cancer. Previous studies in the primary care population have found the diagnostic performance of specific alarm symptoms to be rather poor [7]. Moreover, it has been demonstrated that almost half of cancer patients in general report unspecific symptoms prior to diagnosis [8]. Hence, the non-specific symptoms of malignant disease such as unintended weight loss and tiredness/fatigue are also important to take into consideration in the diagnostic process. Although the predictive values of specific and non-specific alarm symptoms of upper GI cancer in the general population are assumed to be low, this has not yet been investigated. It might be possible that healthcare seeking with alarm symptoms is associated with a higher likelihood of being diagnosed with a serious disease. However, knowledge about the predictive value of upper GI cancer alarm symptoms presented to the GP remains yet to be explored in a prospective study in the general population.

\section{Methods}

\section{Aim}

The aims of this study were 1) to determine the predictive value of specific and non-specific alarm symptoms for subsequent upper GI cancer in the general population over 45 years and 2) to describe the proportion of specific and non-specific alarm symptoms reported by patients prior to diagnosis of upper GI cancer. The duration of follow-up was 12 months.

\section{Study design and population}

The study was designed as a nationwide cohort study based on questionnaires and national registries, imbedded in the Danish Symptom Cohort (DaSC) [9]. From the Danish Civil Registration System (CRS), 100,000 adults aged 20 years or above were randomly selected and invited to participate in a survey. All Danish citizens are registered in the CRS with a unique personal identification number. Prior to the sampling procedure, individuals who had indicated that they did not want research-related inquiries were excluded. Selected individuals received a postal letter explaining the purpose of the study. The questionnaire was designed using the internet-based platform SurveyXact [10]. In the letter a unique 12-digit login for a secure webpage was included. This provided access to a comprehensive web-based questionnaire. In order to prevent exclusion of people with no access to the internet, the participants were offered to complete the survey by telephone interview. When an invited subject was unable to respond due to severe illness or having moved abroad, family or relatives could decline the invitation on behalf of the invited person. The reason for not responding was then simply registered as illness or moved abroad.

\section{The questionnaire}

We developed a comprehensive questionnaire on specific and non-specific cancer alarm symptoms. The questionnaire was based on standard rating scales, previously validated questionnaires and ad hoc items. The methodological framework for developing, piloting and field-testing the questionnaire is described elsewhere [9]. This paper addresses the specific and non-specific alarm symptoms that might indicate upper GI cancer. Symptoms were selected based on a review of literature, national and international cancer referral guidelines and descriptions of cancer pathways [4, 5]. In total, nine predefined symptoms form the base of this paper (Table 1).

Respondents were asked whether they had experienced one or more of the symptoms within the preceding four weeks. Further, they were asked whether they had contacted their GP regarding the symptom. The wording of the question regarding symptom experience was: "Have you experienced any of the following sensations, symptoms or discomfort within the past four weeks?". Respondents select one or more of the predefined symptoms. With regard to GP contact, the question was worded: "Have you contacted your general practitioner concerning the symptom(s) you have experienced within the preceding four weeks, by appointment, telephone or e-mail?" An item concerning when the symptom(s) occurred for the first time was also included. The response categories were: "Less than one 
Table 1 Specific and non-specific symptoms of upper gastrointestinal (Gl) cancer

\begin{tabular}{ll}
\hline $\begin{array}{l}\text { Specific alarm symptoms } \\
\text { of upper Gl cancer }\end{array}$ & $\begin{array}{l}\text { Prevalence estimates of } \\
\text { the symptoms ( }(\%)), \\
N=33,040\end{array}$ \\
Repeated vomiting & $350(1.1 \%)$ \\
Difficulty swallowing & $1119(3.4 \%)$ \\
Upper Gl bleeding $^{\text {a }}$ & $454(1.4 \%)$ \\
Persistent and recent-onset & $832(2.5 \%)$ \\
abdominal pain & \\
Non-specific alarm symptoms & \\
of upper Gl cancer & \\
Nausea & $3040(9.2 \%)$ \\
Weight loss & $859(2.6 \%)$ \\
Loss of appetite & $1586(4.8 \%)$ \\
Feeling unwell & $3502(10.6 \%)$ \\
Tiredness & $13,745(41.6 \%)$ \\
\hline
\end{tabular}

aUpper Gl bleeding comprises experiencing 'Blood in vomit' and 'Black stool' b'Persistent and recent-onset abdominal pain' comprises experiencing 'Abdominal pain' for the first time more than one month ago but less than six months ago

month ago", "1-3 months ago", "3-6 months ago" or "more than six months ago".

\section{Register data}

Information on diagnoses of upper GI cancer was retrieved from the Danish Cancer Registry (DCR). The DCR contains personal and tumour characteristics for all incident cancer cases in Denmark including date of diagnosis and ICD-10 codes for the lesions [11] . Only cases diagnosed in a 12-month period after the completion of the questionnaire were included. Furthermore, cases were excluded if the individual had been diagnosed with the same ICD-10 code in a time period covering five years prior to the completion of the questionnaire. The ICD-10 codes used for this study are listed in Table 2.

\section{Statistical analyses}

Positive predictive values (PPVs) were calculated by dividing the number of symptomatic individuals diagnosed with upper GI cancer by the total number of symptomatic individuals in each category and are presented as percentages. PPVs for upper GI cancer were calculated for: 1) at least one of the nine alarm

Table 2 ICD10 codes used for incident cancer cases

\begin{tabular}{ll}
\hline ICD10 diagnose code & Name \\
\hline DC15+DC16 & $\begin{array}{l}\text { Neoplasma malignum oesophagi + Neoplasma } \\
\text { malignum ventriculi }\end{array}$ \\
DC150-DC159, excl. & $\begin{array}{l}\text { Malignant neoplasm in various parts of } \\
\text { esophagus and stomach. }\end{array}$ \\
DC159X & \\
DC160-DC169 excl. & \\
DC169X & \\
\hline
\end{tabular}

symptoms, 2) at least one of the specific alarm symptoms, 3) at least one of the non-specific alarm symptoms and 4) GP contact with at least one of the nine alarm symptoms. We chose to include positive likelihood ratios $(\mathrm{LR}+)$ as a relative measure of the association between symptom experience and upper GI cancer. This was done because we expected that the incidence of upper GI cancer would be low compared to the incidence of upper GI symptoms. Therefore, the numerator would be much smaller than the denominator when calculating the PPVs, running the risk of attenuating the association between symptom experience and upper GI cancer. The proportions of alarm symptoms reported by individuals diagnosed with upper GI cancer are presented. Confidence intervals were calculated using a binomial distribution.

All statistical tests used a significance level of $P<0.05$. Data analyses were conducted using STATA statistical software 13.1 (StataCorp, College Station, TX, USA).

\section{Results}

Of the 100,000 randomly selected subjects, 4474 (4.7\%) were not eligible because they had either died, could not be reached due to an unknown address, were suffering from severe illnesses (including dementia), had language problems or had moved abroad. A total of 95,253 subjects were eligible for the study, of these 60,562 were $\geq 45$ years of age. Of the 60,562 subjects, 33,040 completed the questionnaire, yielding an overall response rate of $54.6 \%$ (Fig. 1). The median age of the respondents in the group of respondents above 45 years was 60 years (interquartile range 52-68) compared to 63 years (interquartile range 53-73) for non-respondents. Slightly more respondents were women $(52.4 \%)$ compared to nonrespondents (51.0\%). Details of the responder analysis of the questionnaire is described elsewhere [12].

We found that the specific alarm symptoms of upper GI cancer were infrequent in the general population (Table 1). 'Difficulty swallowing' was the most frequently reported symptom, reported by 1119 (3.4\%) of the respondents. The non-specific alarm symptoms were more common. 'Tiredness' was reported by 13,745 (41.6\%) of the respondents.

In total, 18 respondents were diagnosed with upper GI cancer within the 12 month follow-up period after questionnaire completion. The number of incident upper GI cancers was similar among eligible non-respondents $(14 / 27,522)$. The median age of the respondents diagnosed with upper GI cancer was 69.0 years.

The PPVs for being diagnosed with upper GI cancer ranged between $0.1 \%$ (95\%-CI: $0.0-0.1)$ for at least one of the nine specific and non-specific cancer alarm symptoms and $0.2 \%(95 \%-\mathrm{CI}: 0.1-0.3)$ for at least one of the 
Sampling frame: 100000 randomly selected Danish people aged 20 years or more

$($ men $=48910$ (48.9\%), women $=51090$ (51.1\%)

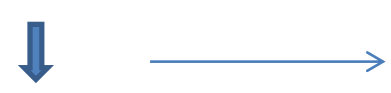

Eligible for the study: 95253 (95.3\%)
Excluded: 4747 (4.7\%)

Dead: 315

Addresses unknown: 961

Suffering from severe illness (including

dementia): 1972

Language problems: 885

Moved abroad: 614

Age <45: $34691(36.4 \%)$

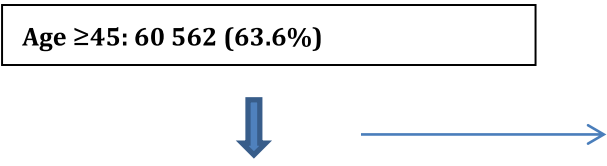

Non-respondents aged $\geq 45: 27522$

(45.4\%)

Respondents aged $\geq 45$ : $33040(54.6 \%)$

$($ men $=15726(47.6 \%)$, women $=17314$

$(52.4 \%))$

Fig. 1 Study cohort

specific alarm symptoms that led to a GP contact, respectively (Table 3 ).

The LR+ for the association between symptoms and upper GI cancer are given in Table 3, Individuals experiencing a specific alarm symptom had a LR+ of 4.4 for being diagnosed with upper GI cancer, whereas individuals experiencing a non-specific symptom had a $\mathrm{LR}+$ of 1.1 .

Of the 18 individuals diagnosed with upper GI cancer, $66.7 \%$ had experienced at least one of the nine alarm symptoms, while $33.3 \%$ had experienced at least one of the four specific alarm symptoms.

In total, $38.9 \%$ of the individuals diagnosed with upper GI cancer reported that they had contacted the GP with at least one of the nine symptoms.

\section{Discussion}

\section{Main findings}

In this study we investigated the PPVs of specific and non-specific alarm symptoms of upper GI cancer in the general population. The PPVs were generally very low; the highest PPV was found among individuals who experienced at least one specific alarm symptom (0.2\%) and among individuals who contacted the GP with at least one alarm symptom (0.2\%). In total, $66.7 \%$ of the individuals diagnosed with upper GI cancer had reported experiencing at least one alarm symptom in the 12-month period prior to diagnoses. The LR+ was substantially higher for individuals experiencing a specific alarm
Table 3 Positive predictive values and positive likelihood ratios for upper Gl cancers divided by specific and non-specific upper Gl cancer alarm symptoms experienced in the general population

\begin{tabular}{|c|c|c|}
\hline \multicolumn{2}{|c|}{$\begin{array}{l}\text { Cases of upper Gl cancers, numbers (N, \%), positive } \\
\text { predictive values, PPV (\%) with } 95 \%-\mathrm{Cl} \text { and positive } \\
\text { likelihood ratios (LR+) }\end{array}$} & \multirow{2}{*}{$\begin{array}{l}\text { Total } \\
12 \text { (66.7\%) }\end{array}$} \\
\hline At least one alarm symptom & $N(\%)$ & \\
\hline & PPV & 0.1 \\
\hline & $95 \% \mathrm{Cl}$ & $(0.0 ; 0.1)$ \\
\hline & $\mathrm{LR}+$ & 1.4 \\
\hline & $95 \% \mathrm{Cl}(\mathrm{LR}+)$ & $(1.0 ; 1.9)$ \\
\hline \multirow[t]{5}{*}{ At least one specific alarm symptom } & N (\%) & $6(33.3 \%)$ \\
\hline & PPV & 0.2 \\
\hline & $95 \% \mathrm{Cl}$ & $(0.1 ; 0.5)$ \\
\hline & LR+ & 4.4 \\
\hline & $95 \% \mathrm{Cl}(\mathrm{LR}+)$ & $(0.7 ; 1.7)$ \\
\hline \multirow[t]{5}{*}{ At least one non-specific alarm symptom } & N (\%) & $9(50.0 \%)$ \\
\hline & PPV & 0.1 \\
\hline & $95 \% \mathrm{Cl}$ & $(0.0 ; 0.1)$ \\
\hline & LR+ & 1.1 \\
\hline & $95 \% \mathrm{Cl}(\mathrm{LR}+)$ & $(2.3 ; 8.4)$ \\
\hline \multirow{5}{*}{$\begin{array}{l}\text { Symptom experience and GP contact } \\
\text { with at least one alarm symptom }\end{array}$} & N (\%) & 7 (38.9\%) \\
\hline & PPV & 0.2 \\
\hline & $95 \% \mathrm{Cl}$ & $(0.1 ; 0.3$ \\
\hline & $\mathrm{LR}+$ & 2.8 \\
\hline & $95 \% \mathrm{Cl}(\mathrm{LR})$ & $(1.6 ; 5.0)$ \\
\hline
\end{tabular}


symptom (LR+4.4), whereas experiencing a non-specific alarm symptom was not associated with upper GI cancer $(\mathrm{LR}+1.1)$.

\section{Strengths and limitations}

The major strength of this study is the prospective cohort design, which gives the opportunity to retrieve information about symptom experiences prior to diagnosis. Using this study design we minimized the risk of recall bias that is often a challenge in studies regarding pre-diagnostic symptoms among cancer patients. Using register-based diagnoses rather than asking the respondents further reduces the risk of recall bias. The DCR was used to identify cases of cancer. This registry is based on mandatory data from several sources and is considered to be quite accurate [11].

In order to evaluate the relationship between symptoms and subsequent cancer diagnosis, we chose to include all upper GI cancers diagnosed in a time period of 12 months after reporting one or more of the alarm symptoms. We chose this time limit in order to enhance the likelihood of the symptom being linked to an underlying cancer. However, longer follow-up period might have contributed to a larger number of incident cancers, but we believe that increasing the time limit would weaken the linkage between symptom experience and subsequent diagnosis.

A general weakness of questionnaire-based studies is that respondents may not interpret the questions and categories of answers as intended. Prior to the survey, we conducted several rounds of pilot testing and field testing to reduce this possibility [9]. Based on the results of the pilot testing, it seemed reasonable to assume that the respondents understood the questions as intended.

This study reflects self-reported experience of symptoms and subsequent contacts with a GP. We asked whether the symptom was experienced within the preceding four weeks. Although we asked for symptom experiences and GP contacts within a short time period, some memory decay cannot be ruled out. The invitational letter for the questionnaire stated that this was a survey regarding symptoms, signs and healthcare seeking. A certain amount of social desirability bias cannot be ruled out, given that respondents may have felt that they should report a GP contact about an alarm symptom.

Another limitation is that we do not know if the symptom was a one-time experience that quickly resolved, or an ongoing/persistent symptom. The likelihood of the alarm symptom being caused by malignancy is likely to be very small if the symptom resolves spontaneously.

Another limitation is that more respondents were females and had a higher socioeconomic status compared to non-responders. It is well-known that persons with a lower risk of e.g. cancer are more likely to participate in surveys and even in cancer screening programs [13]. In our study it could have biased the results if the incidence of upper GI cancers had differed between responders and non-response. However, the incidence was similar in the two groups.

Since the incidence of upper GI cancer is relatively low in Denmark with only 18 cases of upper GI cancer in the 12-month follow up, it would have been preferable to estimate PPVs for each of the symptoms separately. However, this was not possible due to the size of the dataset according to Danish regulation. Using the absolute measure of PPV we cannot rule out that some associations were overlooked due to lack of power. Therefore, we chose to include the relative measure LR+ as well to enlighten the strength of association between the symptoms and cancer.

\section{Comparison with existing literature}

The sensitivity and specificity of upper GI cancer alarm symptoms as well as the LR+ of the alarm symptoms have previously been demonstrated to be low among primary care patients [7] as well as in mixed cohorts from primary and secondary health care $[14,15]$. In this study we confirmed that the predictive values of alarm symptoms of upper GI cancer in the general population are low. Based on existing knowledge about the diagnostic performance of symptoms indicative of upper GI cancer and the knowledge about how common GI symptoms are [16], we expected that the symptoms would not exhibit strong specificity despite being denoted cancer alarm symptoms.

An important aspect likely to influence the predictive value of a symptom is the severity of the symptom. Neither this study nor other studies included symptom severity [7], though it is an important factor in the clinical setting to triage of patients for referral.

\section{Conclusions}

We found that the PPVs for alarm symptoms of upper GI cancer are quite low. Furthermore, we found that patients diagnosed with an upper GI malignancy had a higher likelihood of having experienced a specific alarm symptom of upper GI cancer 12 months prior to diagnosis, whereas there was no association between upper GI cancer and experience of non-specific alarm symptoms.

The responder analysis showed that more respondents were females, married/living together, had a high education and income level and were attached to the labour market.

Future studies focusing on the predictive values of different combinations of alarm symptoms could provide further insights. However, given the infrequent diagnosis of upper GI cancer this would require studying an ever larger population. 
Despite the fact that symptoms are not as precise as a diagnostic tool such as e.g. laboratory data, because of their subjective and individual nature, quantifying the association between symptoms and upper GI cancer and comparing the relative diagnostic values is useful knowledge for the clinician.

Similarly, the results are helpful for health service planning. As the prognosis of upper GI cancer depends on stage at diagnosis, a logical instrument to improve survival could be to liberalise criteria for endoscopy. With more liberalised criteria for endoscopy some cancers could be detected earlier. However, given the low predictive value of specific and non-specific alarm symptoms it would result in considerable clinical and economic consequences and campaigns to increase awareness of symptoms of upper GI cancer have failed to demonstrate a significant impact on detection rate [17]. Furthermore, referring more patients for fast track investigations of symptoms that could be signs of cancer, but could just as well be due to other causes than cancer, could have harmful consequences $[18,19]$.

The findings of this study do not give rise to changing current guidance for referral for possible cancer. However, some symptoms such as nausea and abdominal pain are associated with low risk of upper GI cancer; hence these symptoms can be classified as "low risk but not no risk" symptoms [20].

In conclusion, new onset of alarm symptoms of upper GI cancers shows low predictive value for a diagnosis of upper GI cancer within the next year. Highest PPVs were found among individuals who reported experiencing specific alarm symptoms and among individuals who decided to consult their GP regarding alarm symptoms indicative of upper GI cancer. For the GP it is useful to know that despite experiencing alarm symptoms the risk of actually having upper GI cancer is low. This can among others be used in the communication with patients referred for fast track endoscopy. It is possible that being aware of the fact that alarm symptoms most often are not associated with upper GI cancer could reduce the anxiety known to be related to undergoing diagnostic evaluation for possible cancer [21].

\section{Abbreviations \\ CRS: Civil Registration System; DCR: Danish Cancer Registry; GI: Gastrointestinal; GP: General practitioner; LR+: Positive likelihood ratio; PPV: Positive predictive value}

\section{Acknowledgements}

The initial survey was conducted in collaboration between the Research Unit for General Practice, University of Southern Denmark and the Research Centre for Cancer Diagnosis in Primary Care, Aarhus University. We would like to thank Sandra Elnegaard for collaboration on data collection, Maria Munch Storsveen for statistical assistance and Wade Thompson for proofreading the manuscript.

\section{Funding}

This study is financially supported by the Region of Southern Denmark. The funding body had no influence on the design, analysis, interpretation or writing the manuscript.

\section{Availability of data and materials}

The datasets generated and analysed during the current study are not publicly available due to the data protection regulations of the Danish Data Protection, Statistics Denmark and the Danish Health and Medicines Authority. Access to data is strictly limited to the researchers who have obtained permission for data processing. This permission was granted to the Research Unit of General Practice, Department of Public Health, University of Southern Denmark.

\section{Authors' contributions}

SR, DEJ, JS and KB participated in the design of the study. SR, DEJ and KB participated in development of the logistics concerning the survey and collected the data. SR, KB and RDC analysed the data. PFH, SR, JS and DEJ interpreted the data and PFH, SR and DEJ drafted the first version of the manuscript. All authors have revised the manuscript critically for important intellectual content, approved the final manuscript and agreed to be accountable for all aspects of the work.

\section{Ethics approval and consent to participate}

The Regional Scientific Ethics Committee for Southern Denmark evaluated the project and concluded that the project was not notifiable and could be implemented without the permission from The Regional Scientific Ethical Committee for Southern Denmark according to Danish law. The Scientific Ethics Committee's evaluation comprised all aspects of the project including the data collection. Answering the questionnaire was completely voluntary and unpaid. All respondents consented to transmission of information about diagnoses from the Danish national health registries. The participants in the study were clearly informed that there would be no clinical follow-up and that they should contact their own GP in case of concern or worry. The project has been approved by the Danish Data Protection Agency (journal number 2011-41-6651).

\section{Consent for publication}

When answering the questionnaire all respondents gave consent to publication of data.

\section{Competing interests}

The authors declare that they have no competing interests.

\section{Publisher's Note}

Springer Nature remains neutral with regard to jurisdictional claims in published maps and institutional affiliations.

Received: 26 October 2017 Accepted: 16 April 2018

Published online: 18 April 2018

\section{References}

1. Rodriguez-Camacho E, Pita-Fernandez S, Pertega-Diaz S, Lopez-Calvino B, Seoane-Pillado T. Clinical-pathological characteristics and prognosis of a cohort of oesophageal cancer patients: a competing risks survival analysis. J Epidemiol. 2015;25(3):231-8.

2. Elliss-Brookes L, McPhail S, Ives A, Greenslade M, Shelton J, Hiom S, Richards M. Routes to diagnosis for cancer - determining the patient journey using multiple routine data sets. Br J Cancer. 2012;107(8):1220-6.

3. McPhail S, Elliss-Brookes L, Shelton J, Ives A, Greenslade M, Vernon S, Morris EJ, Richards M. Emergency presentation of cancer and short-term mortality. Br J Cancer. 2013;109(8):2027-34.

4. The Danish National Board of Health: Pakkeforløb for kræft i spiserør, mavesæk og mavemund [Cancer package for eosophageal, stomach and cardia cancer]. 2012

5. National Institute for Health and Clinical Excellence. Referral guidelines for suspected cancer. London: NICE; 2005.

6. Rasmussen S, Larsen PV, Svendsen RP, Haastrup PF, Sondergaard J, Jarbol DE. Alarm symptoms of upper gastrointestinal cancer and contact to general practice-a population-based study. Scand J Gastroenterol. 2015; 50(10):1268-75 
7. Astin MP, Martins T, Welton N, Neal RD, Rose PW, Hamilton W. Diagnostic value of symptoms of oesophagogastric cancers in primary care: a systematic review and meta-analysis. Br J Gen Pract. 2015;65(639):e677-91.

8. Nielsen TN, Hansen RP, Vedsted P. Symptom presentation in cancer patients in general practice. Ugeskr Laeger. 2010;172(41):2827-31.

9. Rasmussen S, Sondergaard J, Larsen PV, Balasubramaniam K, Elnegaard S, Svendsen RP, Andersen RS, Pedersen AF, Vedsted P, Jarbol DE. The Danish symptom cohort: questionnaire and feasibility in the Nationwide study on symptom experience and healthcare-seeking among 100000 individuals. Int J Family Med. 2014;2014:187280.

10. Rambøll Management Consulting: SurveyXact. 2012.

11. Gjerstorff ML. The Danish Cancer registry. Scand J Public Health. 2011;39(7 Suppl):42-5.

12. Elnegaard $\mathrm{S}$, Andersen RS, Pedersen AF, Larsen PV, Sondergaard J, Rasmussen S, Balasubramaniam K, Svendsen RP, Vedsted P, Jarbol DE. Selfreported symptoms and healthcare seeking in the general populationexploring "the symptom iceberg". BMC Public Health. 2015;15:685.

13. Petti S, Scully C. How many individuals must be screened to reduce oral cancer mortality rate in the western context? A challenge. Oral Dis. 2015; 21(8):949-54.

14. Vakil N, Moayyedi P, Fennerty MB, Talley NJ. Limited value of alarm features in the diagnosis of upper gastrointestinal malignancy: systematic review and meta-analysis. Gastroenterology. 2006;131 (2):390-401. quiz 659-360

15. Fransen GA, Janssen MJ, Muris JW, Laheij RJ, Jansen JB. Meta-analysis: the diagnostic value of alarm symptoms for upper gastrointestinal malignancy. Aliment Pharmacol Ther. 2004:20(10):1045-52

16. Rasmussen S, Jensen TH, Henriksen SL, Haastrup PF, Larsen PV, Sondergaard J, Jarbol DE. Overlap of symptoms of gastroesophageal reflux disease, dyspepsia and irritable bowel syndrome in the general population. Scand J Gastroenterol. 2015:50(2):162-9.

17. Koo S, Awadelkarim B, Dhar A. The National Oesophagogastric Cancer Awareness Campaign: a locality outcome analysis from county Durham. Frontline Gastroenterol. 2017;8(4):290-4.

18. Longstreth GF, Thompson WG, Chey WD, Houghton LA, Mearin F, Spiller RC. Functional bowel disorders. Gastroenterology. 2006;130(5):1480-91.

19. Brocken P, Prins JB, Dekhuijzen PN, van der Heijden HF. The faster the better?-a systematic review on distress in the diagnostic phase of suspected cancer, and the influence of rapid diagnostic pathways. Psycho-Oncology. 2012:21(1):1-10.

20. Hamilton W. Cancer diagnosis in primary care. Br J Gen Pract. 2010;60(571): $121-8$.

21. Moseholm E, Rydahl-Hansen S, Overgaard D, Wengel HS, Frederiksen R, Brandt $\mathrm{M}$, Lindhardt BO. Health-related quality of life, anxiety and depression in the diagnostic phase of suspected cancer, and the influence of diagnosis. Health Qual Life Outcomes. 2016;14:80.

\section{Ready to submit your research? Choose BMC and benefit from:}

- fast, convenient online submission

- thorough peer review by experienced researchers in your field

- rapid publication on acceptance

- support for research data, including large and complex data types

- gold Open Access which fosters wider collaboration and increased citations - maximum visibility for your research: over $100 \mathrm{M}$ website views per year

At BMC, research is always in progress.

Learn more biomedcentral.com/submissions 